\title{
PERENCANAAN STRATEGIS SISTEM INFORMASI MENGGUNAKAN WARD AND PEPPARD DI PERUSAHAAN PT PURA BARUTAMA (UNIT PM1O)
}

\author{
Eliezer Cres Cendo Yobel ${ }^{1)}$ dan Melkior Nikolar Ngalumsine Sitokdana ${ }^{2)}$ \\ ${ }^{1,2}$ Program Studi Sistem Informasi, Fakultas Teknologi Informasi, Universitas Kristen Satya Wacana \\ ${ }^{1,2}$ Jl. Dr. O. Notohamidjodjo. Blotongan, Sidorejo, Salatiga, 50715 \\ E-mail: 682016066@student.uksw.edu ${ }^{1)}$, melkior.sitokdana@uksw.edu²)
}

\begin{abstract}
ABSTRAK
PT Pura Barutama merupakan perusahaan yang bergerak dibidang usaha percetakan security. Unit PM 10 merupakan salah satu dari beberapa unit yang ada di PT Pura Barutama, dimana Unit PM 10 berfokus pada percetakan security paper. Unit PM 10 masih menemui kendala dalam aplikasi Sistem Informasi yang belum mampu mendukung proses bisnis. Dalam penyusunan penelitian perencanaan strategis sistem informasi menggunakan metode Ward and Peppard. Analisis lingkungan internal bisnis menggunakan Value Chain dan SWOT analisis, untuk analisis lingkungan eksternal bisnis menggunakan PEST analisis. Sedangkan untuk pemetaan portofolio aplikasi menggunakan McFarlan Strategic Grid. Pada tahap akhir penelitian ini menghasilkan sebuah rekomendasi yang dapat membantu mengembangkan Unit PM 10 untuk dikembangkan. Rekomendasi yang diberikan antara lain Aplikasi Business Intellegence Gudang Opname, Aplikasi Perhitungan Harga, Aplikasi Mobile Penjualan \& Permintaan, Aplikasi Mobile Stok Gudang, Aplikasi Purchase Request, SI SDM, Sistem Pengelolaan Data, Aplikasi e-training, Aplikasi sertifikasi reminder. Tujuan dari penelitian ini dapat memberikan arah terhadap Unit PM 10 untuk dapat berkembang lebih baik dan mendukung kelangsungan bisnis Unit PM 10 PT Pura Barutama.
\end{abstract}

Kata Kunci: Perencanaan Strategis, Ward and Peppard, Sistem Informasi, McFarlan Strategic Grid, PEST, Value Chain, Portofolio.

\section{PENDAHULUAN}

Penggunaan Teknologi Informasi (TI) dan Sistem Informasi (SI) dibutuhkan untuk meningkatkan daya saing organisasi. Organisasi harus mampu mempersiapkan diri dalam merencanakan penggunaan SI/TI serta menerapkannya sebagai alat bantu dalam memajukan proses bisnis organisasi maupun kegiatan operasional yang ada (Davis \& Yen, 2019). Namun pengembangan strategi SI/TI yang ada harus disesuaikan dengan strategi organisasi agar peran serta fungsi SI/TI tersebut dapat meningkat dan pada akhirnya meningkatkan nilai organisasi itu sendiri. Salah satu organisasi yang sudah menerapkan SI/TI adalah PT Pura Barutama. Perusahaan tersebut bergerak dibidang usaha percetakan security. PT Pura Barutama berawal dari sebuah percetakan letterpress kecil yang berdiri di tahun 1908. Kemudian pada tahun 1970 perusahaan berkembang pesat sampai menjadi industri modern. PT Pura Barutama menghasilkan produk-produk inovatif berteknologi tinggi sebagai pengganti impor di pasar domestik dan produk ekspor untuk pasar internasional. Produk-produk PT Pura Barutama hadir dengan berbagai macam aspek kehidupan baik dalam lingkup pribadi, perusahaan, dan industri. PT Pura Barutama memiliki beberapa divisi dan produk antara lain, Divisi Smart Technology (SIM Card, Smart Card, Tag / Label RFID,
Smart Kiosk, Pengembangan Solusi IT), Divisi Pabrik Kertas (Kertas Uang / Banknote Paper, Kertas Sekuriti / Security Paper, Kertas Khusus, Kertas Komoditi), Divisi Kemasan Cetak Rotogravure (Kemasan Multi Layer, Kemasan Fleksibel Multi Layer, Kotak Lipat \& Kemasan Rokok), Divisi Perekat Industri, dan beberapa divisi produksi pendukungnya.

Berdasarkan banyaknya divisi dan produk yang harus dihasilkan, PT Pura Barutama sangat mengedepankan segala fasilitas Teknologi Informasi untuk meningkatkan produktivitas. Berdasarkan hal tersebut diperlukan perencanaan strategis Sistem Informasi. Dengan perencanaan strategis organisasi bisa melihat dengan objektif kondisi internal dan eksternal, sehingga organisasi dapat melihat ke depan terhadap perubahan lingkungan bisnis.

Hal yang menjadi permasalahan dalam penelitian ini adalah bagaimana merancang sebuah perencanaan strategis SI yang sesuai dengan kebutuhan PT Pura Barutama terkhusus pada unit PM10 sehingga dapat mendukung kinerja PT Pura Barutama (Unit PM10) dalam menjalankan proses bisnisnya. Dalam penelitian ini digunakan metode Ward and Peppard dengan menggunakan beberapa teknik analisis Value Chain, SWOT, PEST untuk menganalisis lingkungan internal dan eksternal bisnis, untuk menganalisis lingkungan 
internal dan eksternal SI maupun TI menggunakan portofolio aplikasi saat ini, dan McFarlan Strategic Girdyang digunakan untuk pemetaan portofolio aplikasi. Penelitian ini diharapkan dapat menghasilkan perencanaan strategis sistem informasi di PT Pura Barutama (Unit PM 10).

Beberapa penelitian terdahulu yang telah dilakukan dan kemudian menjadi acuan dalam penelitian ini berjudul Perancangan Strategis PD BKK Susukan Kabupaten Semarang menggunakan Metode Ward and Peppard (Celta dkk., 2018). Penelitian ini membahas bagaimana PD. BKK Susukan menggunakan SI dan TInya, dan terdapat beberapa kekurangan yang menghasilkan usulan-usulan untuk dijadikan sebagai acuan PD. BKK Susukan dalam mengembangkan SI/TI ke depannya.

Penelitian dengan judul Perencanaan Strategis Sistem Informasi Menggunakan Ward and Peppard Studi kasus: Gereja Kristen Jawa Plengkung (Setyono, Wijaya and Sitokdana, 2018). Adapun hasil pada penelitian ini yaitu bahwa pada GKJ Plengkung Magelang masih terdapat minimnya dukungan penggunaan teknologi, yang kemudian diberikan beberapa usulan-usulan pengembangan teknologi menggunakan McFarlan Strategic Grid untuk dapat membantu GKJ Plengkung Magelang menjadi semakin lebih baik.

Penelitian berjudul Perencanaan Strategis Sistem Informasi Menggunakan Metode Ward and Peppard Pada PT Serasi Autoraya (Rahardja \& Sitokdana, 2019). Pada penelitian ini memberikan hasil bahwa PT Serasi Autoraya masih mempunyai kendala dalam infrastruktur dan aplikasi SI yang masih belum mampu mendukung proses bisnis serta kurangnya implementasi SI yang membuat kinerja menjadi tidak efisien. Berdasarkan hal tersebut penelitian ini merekomendasikan pengembangan Website Trac, aplikasi SAP, aplikasi sistem informasi layanan pelanggan, aplikasi sistem informasi aset dan sistem informasi eksekutif. Rekomendasi tersebut diharapkan dapat memberikan kejelasan arah dan mendorong perusahaan untuk terus berkembang baik dari aspek SDM SI dan pengembangan aplikasi portofolio yang akan mendukung kelangsungan proses bisnis di PT Serasi Autoraya.

Penelitian selanjutnya berjudul Penyusunan Strategi Sistem Informasi / Teknologi Informasi pada Apotek Cahaya Mitra Menggunakan Metode Ward and Peppard(Iskandar, 2016). Penelitian ini menghasilkan bahwa Apotek Cahaya Mitra Solo merupakan apotek yang terkenal di Solo, dengan meningkatnya permintaan masyarakat soal fasilitas kesehatan di Solo, penelitian ini membuat perencanaan strategis SI/TI menggunakan Ward and Peppard dimana hasil dari perencanaan strategis tersebut dapat digunakan oleh Apotek Cahaya Mitra Solo dalam membangun SI/TI di perusahaan agar membantu pekerjaan bisnis perusahaan menjadi lebih efektif dan efisien.

Berdasarkan 4 penelitian yang telah dilakukan sebelumnya menjadi acuan penulis dalam melakukan penelitian ini, dimana hasil dari penelitian ini diharapkan dapat membantu perusahaan dalam memahami arah dan tujuan perusahaan, sehingga PT Pura Barutama (Unit PM10) dapat meningkatkan sistem kerja yang lebih efektif dan efisien.

\section{RUANG LINGKUP PENELITIAN}

Dalam penelitian ini permasalahan mencakup.

1. Cakupan permasalahan dalam penelitian ini.

Unit PM 10 PT Pura Barutama Kudus telah menerapkan SI/TI namun masih ditemukan kekurangan dan belum menerapkan perencanaan strategis sehingga penggunaannya masih kurang. Oleh karena itu, dibutuhkan perencanaan strategis sistem informasi untuk membantu meningkatkan kualitas proses bisnis yang ada.

2. Batasan dalam penelitian ini hanya mengacu pada penerapan perencanaan strategis sistem informasi.

3. Akhir dari hasil penelitian ini menghasilkan rekomendasi portofolio aplikasi yang dapat diimplementasikan dalam 5 tahun ke depan.

\section{BAHAN DAN METODE}

Berikut dipaparkan bahan kajian, metode serta tahapan penelitian yang dilakukan.

\subsection{Sistem Informasi}

Sistem Informasi merupakan sebuah keterkaitan antara manusia, prosedur, serta penggunaan teknologi yang digunakan untuk mengumpulkan, mengolah, menyimpan, menyebarkan dan menyajikan informasi yang digunakan oleh suatu proses bisnis dalam organisasi (Grant dkk., 2010).

Sistem Informasi adalah sebuah perangkat dengan menggunakan teknologi untuk mengumpulkan, memproses, menyimpan, menyebarkan, dan menyajikan informasi yang dibutuhkan oleh suatu organisasi. Teknologi Informasi adalah pemanfaatan teknologi terutama hardware, software, dan telecommunication networks baik tangible dan intangible sebagai fasilitas untuk acquisition, processing, stroring, delivery dan sharing of information. TI berguna untuk menyediakan fasilitas dalam berjalannya seluruh proses dan fungsi sistem informasi secara berkelanjutan (Anggraeni, 2017).

\subsection{Perencanaan Strategis Sistem Informasi}

Perencanaan Strategis merupakan sebuah perencanaan jangka panjang dengan memberikan rumusan kepada organisasi/perusahaan terhadap bagaimana cara sumber daya digunakan untuk mencapai tujuan dalam jangka waktu tertentu. Untuk mendapatkan penerapan perencanaan SI/TI yang optimal, diperlukan sebuah strategi SI/TI yang selaras dengan strategi bisnis perusahaan/organisasi. Ini perlukan agar investasi yang dikeluarkan sesuai dengan kebutuhan organisasi serta dapat memberikan manfaat. Untuk menentukan strategi SI/TI yang dapat membantu mencapai tujuan organisasi/perusahaan, diperlukan pemahaman tentang 
strategi bisnis organisasi/perusahaan yang mencakup penjelasan terhadap mengapa suatu bisnis dijalankan, tujuan ingin dicapai, kapan tujuan tersebut akan dicapai, bagaimana cara mencapai tujuan tersebut serta perubahan apa yang harus dilakukan.

Perencanaan strategis sistem informasi merupakan pendekatan sistematis untuk menentukan mana yang paling efektif dan efisien berkaitan dengan kepuasan untuk memenuhi kebutuhan informasi (Suryana, 2012) Perencanaan strategis diperlukan untuk membantu perusahaan dalam mempersiapkan perencanaan menggunakan teknologi serta sistem informasi.

Keunggulan strategis dan kompetitif serta kaitannya dengan strategi bisnis, arahan dari eksekutif atau manajemen senior dan pengguna, serta pendekatan berupa invasi pengguna dan kombinasi pengembangan bottom up dan analisa top down merupakan karakteristik utama dari perencanaan strategis SI/TI (Irwansyah \& Moniaga, 2014.)

\subsection{Metodologi Ward and Peppard}

Metodologi Ward and Peppard diawali dengan kondisi SI/TI dimasa lalu yang kurang bermanfaat bagi perusahaan, kemudian dilanjutkan dengan menangkap peluang bisnis, serta meningkatkan keunggulan kompetitif perusahaan. Metodologi Ward and Peppard yang digunakan dalam penelitian ini dapat dilihat dari Gambar 1.

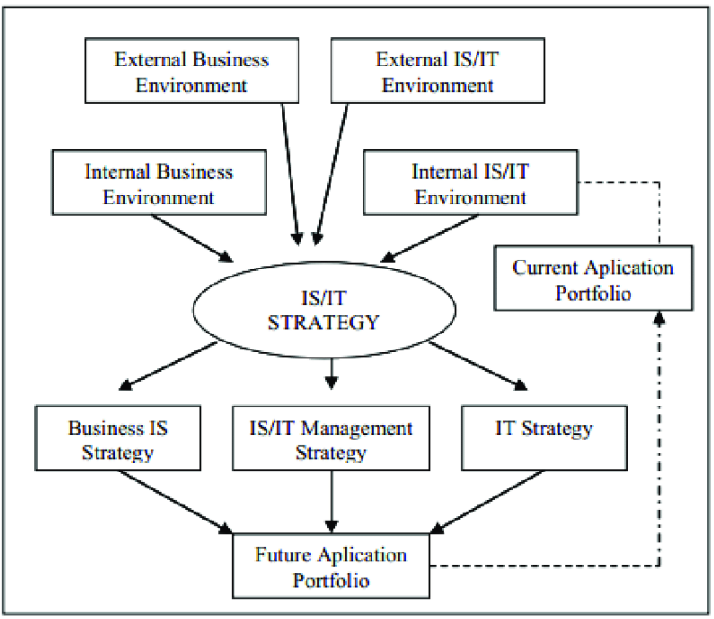

Gambar 1. Metode Perencanaan Strategis SI/TI (Ward \& Peppard, 2016)

Metodologi Ward and Peppard dapat dijelaskan. Tahapan Masukan adalah sebagai berikut:

1. Analisis lingkungan bisnis internal, mencakup aspek strategi bisnis, sasaran, sumber daya, proses, dan budaya organisasi.

2. Analisis lingkungan bisnis eksternal, mencakup aspek ekonomi, industri, serta kondisi daya saing perusahaan.

3. Analisis lingkungan SI/TI internal, mencakup kondisi SI/TI organisasi berdasarkan kondisi bisnis saat ini, kematangan (maturity), kontribusi terhadap bisnis, keterampilan sumber daya manusia, sumber daya dan infrastruktur teknologi, serta portofolio SI/TI yang ada saat ini.

4. Analisis lingkungan SI/TI eksternal, mencakup tren teknologi dan pemanfaatannya, serta penggunaan SI/TI oleh kompetitor, pelanggan dan pemasok.

Sedangkan tahapan keluaran adalah sebagai berikut:

1. Strategi bisnis Sistem Informasi, mencakup bagaimana setiap fungsi bisnis menggunakan SI/TI dalam mencapai tujuan bisnisnya, portofolio aplikasi serta arsitektur informasinya.

2. Strategi Teknologi Informasi, mencakup aturanaturan dan strategi untuk pemanfaatan teknologi serta sumber daya SI/TI-nya.

3. Strategi Manajemen SI/TI, mencakup elemen-elemen umum yang dilakukan oleh organisasi, dalam memastikan konsistensi kebijakan SI/TI yang dibutuhkan.

\subsection{Tahapan Penelitian}

Dalam penelitian ini metode yang digunakan adalah kualitatif. Metode kualitatif merupakan sebuah pengamatan, wawancara, atau menelaah dokumen. Metode ini digunakan dalam penelitian ini karena penyesuaian kualitatif lebih mudah apabila berhadapan dengan kenyataan, kemudian kualitatif menyajikan secara langsung hakikat hubungan antara peneliti dan responden. Pada penelitian ini dilakukan dengan beberapa tahap penelitian, yang dapat dilihat dari Gambar 2.

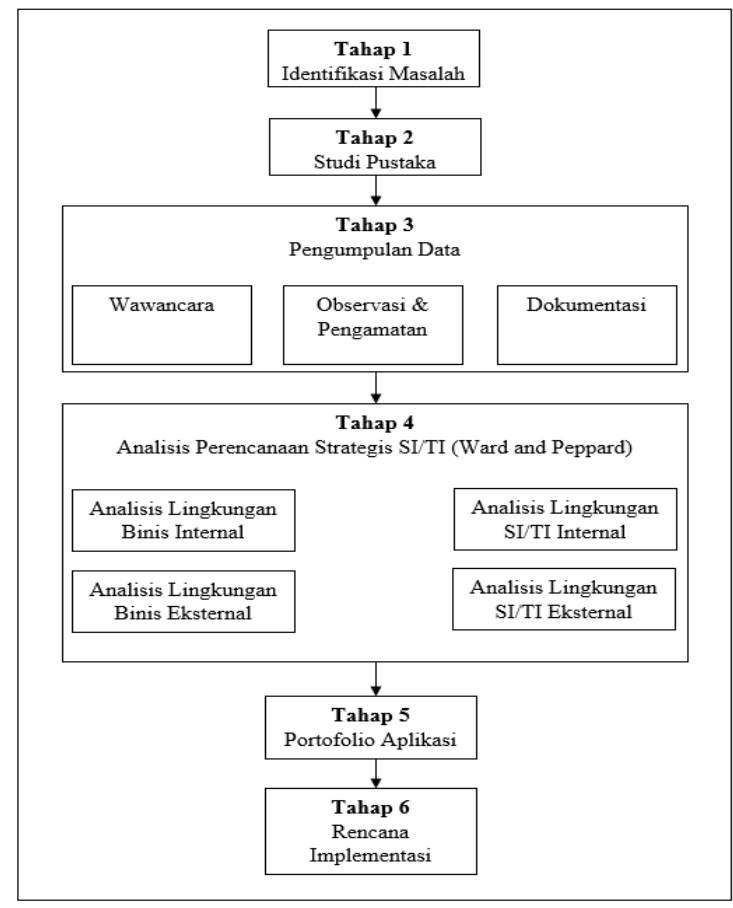

Gambar 2. Tahapan Penelitian 
Penelitian ini dilakukan dengan beberapa tahap, antara lain.

1. Identifikasi Masalah

Identifikasi masalah adalah proses peneliti mendapatkan gambaran tentang permasalahan yang sedang dialami oleh perusahaan, dimana hasil akhirnya memberikan solusi dengan proses observasi.

2. Tinjauan Pustaka

Tahap ini melakukan tinjauan berbagai penelitian terdahulu dan teori yang relevan untuk dijadikan sebagai landasan dalam penelitian ini.

3. Pengumpulan Data

Penelitian ini dilakukan dengan pengamatan lingkungan sekitar untuk memperoleh data yang dibutuhkan yang sesuai dengan kebutuhan perencanaan strategis SI/TI. Dalam pengumpulan data peneliti menggunakan beberapa teknik, antara lain.

1) Wawancara

Wawancara dilakukan pada Staf MIS dan Staf Bag. Teknik Listrik \& Instrumen Unit PM 10 PT Pura Barutama pada tanggal $3-7$ September 2019 dilanjutkan dengan bagian HR pada tanggal 20-28 Februari 2020.

2) Observasi dan Pengamatan.

Observasi dan Pengamatan dilakukan pada tanggal 8 September 2019 - 28 Februari 2020.

3) Dokumentasi.

Menganalisis visi dan misi, struktur organisasi, struktur diagram SI/TI dan proses yang ada di lapangan. Data tersebut nantinya yang akan digunakan sebagai acuan dalam menjalankan perencanaan strategis di Unit PM 10 PT Pura Barutama Kota Kudus.

4. Analisis Perencanaan Strategis Sistem Informasi Menggunakan Ward and Peppard.

1) Analisis lingkungan bisnis, pada tahap ini dalam menganalisis kondisi bisnis internal menggunakan metode SWOT dan Value Chain, kemudian untuk kondisi bisnis eksternal menggunakan metode PEST.

2) Analisis lingkungan SI/TI, pada tahap ini dalam menganalisis kondisi SI/TI internal dan eksternal menggunakan gambaran portofolio SI/TI saat ini.'

3) Portofolio aplikasi, dalam hal ini bertujuan untuk menemukan sistem informasi yang cocok untuk pengembangan aplikasi. Metode yang dipakai menggunakan metode McFarlan Strategic Grid. Penyusunan kebutuhan SI/TI disesuai dengan hasil analisis yang sudah dilakukan. Sehingga menghasilkan rancangan strategi SI/TI ke depan untuk Unit PM 10 PT Pura Barutama.

4) Rencana Implementasi

Rencana Implementasi yang disarankan untuk dapat di implementasikan adalah dalam jangka waktu 5 tahun.

\section{PEMBAHASAN}

Berikut penyusunan perencanaan strategis sistem informasi pada Unit PM 10 PT Pura Barutama Kudus menggunakan metode Ward and Peppard.

\subsection{Analisis Lingkungan Bisnis Internal dan}

Eksternal

Dalam analisis lingkungan bisnis internal dan eksternal terbagi menjadi beberapa analisis berikut:

\subsubsection{Analisis Value Chain}

Analisis Value Chain dilakukan untuk menggambarkan aktivitas proses bisnis utama serta aktiivitas pendukung organisasi/perusahaan. Hasil dari Value Chain Unit PM 10 PT Pura Barutama Kudus dapat dilihat dari Gambar 3.

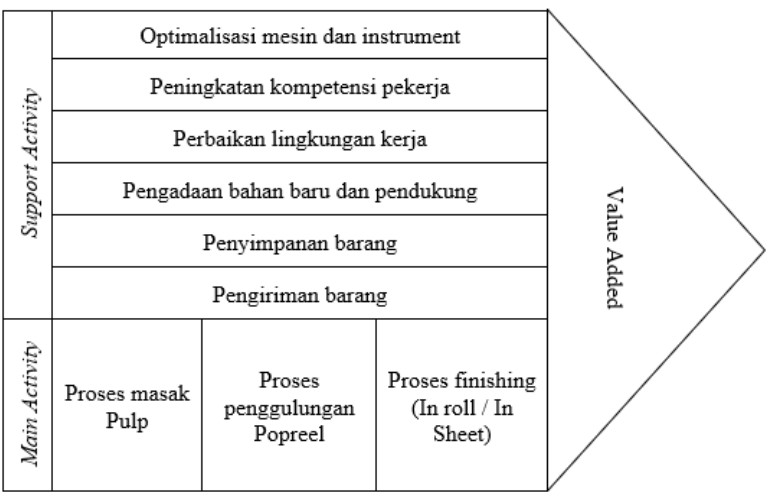

Gambar 3. Diagram Value Chain

Berdasarkan Gambar 3. dapat dilihat aktivitas utama serta aktivitas pendukung, antara lain:

1. Aktivitas Utama (Main Activity)

1) Proses masak pulp

2) Proses penggulungan Popreel

3) Proses finishing (In Roll / In Sheet)

2. Aktivitas Pendukung (Support Activity)

1) Optimalisasi mesin dan instrument

2) Peningkatan kompetensi pekerja

3) Perbaikan lingkungan kerja

4) Pengadaan bahan baru dan pendukung

5) Penyimpanan barang

\subsubsection{Analisis SWOT}

Analisis SWOT (Strength, Weakness, Opportunity, Threat) digunakan dalam menilai kondisi keseluruhan sumber daya yang dimiliki oleh perusahaan atau organisasi. Analisis SWOT akan dipetakan dari hasil analisis kondisi lingkungan pada Unit PM 10. Berikut SWOT Unit PM 10 PT Pura Barutama Kudus dapat dilihat dari Tabel 1. 
Tabel 1. Analisis SWOT

\begin{tabular}{|c|c|c|}
\hline Internal & \begin{tabular}{|l} 
Kekuatan \\
STRENGTHS $(\boldsymbol{S})$ \\
1) \\
2) \\
Mayoritas karyawan berusia muda \\
Seluruh bagian komputer sudah \\
terhubung dalam satu jaringan \\
3) \\
Mengembangkan aplikasi sendiri \\
Menembangkan mesin sendiri \\
5) \\
Memiliki fasilitas TI yang sudah \\
memadai
\end{tabular} & \begin{tabular}{|l} 
Kelemahan \\
WEAKNESSES $(\boldsymbol{W})$ \\
1) \\
Beberapa pola/sistem lama \\
masih dipertahankan \\
Karyawan yang kurang paham \\
dalam menggunakan sistem \\
3) \\
Kurang responsif aplikasi \\
karena data yang banyak \\
tertumpuk
\end{tabular} \\
\hline Eksternal & & \\
\hline 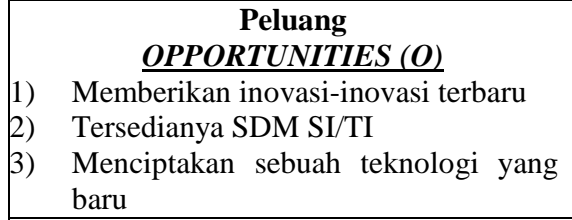 & \begin{tabular}{|l} 
STRATEGI S-O \\
1) $\begin{array}{l}\text { Meningkatkan nilai jual dari } \\
\text { perusahaan terkhusus unit PM } 10 \\
\text { Menjadi penyedia kebutuhan berbagai } \\
\text { jenis kertas }\end{array}$
\end{tabular} & \begin{tabular}{|ll}
\multicolumn{2}{|c}{ STRATEGI W-O } \\
1) & $\begin{array}{l}\text { Mengembangkan } \\
\text { pola yang baru }\end{array}$ \\
2) & Memberikan \\
& terhadap karyawan
\end{tabular} \\
\hline 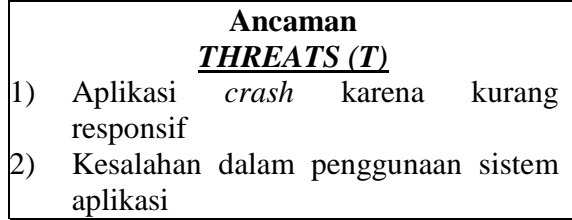 & $\begin{array}{c}\text { STRATEGI S-T } \\
\text { Meningkatkan kualitas aplikasi }\end{array}$ & \begin{tabular}{lr}
\multicolumn{2}{c}{ STRATEGI W-T } \\
Meningkatkan & kualitas \\
pemahaman & karyawan \\
terhadap sistem &
\end{tabular} \\
\hline
\end{tabular}

Keterangan pada Tabel 1.

Strength.

1. Mayoritas karyawan berusia muda, hal tersebut menjadi kekuatan bagi Unit PM 10 karena dengan karyawan yang berusia muda memiliki tenaga dan pemikiran yang lebih sehingga dapat memberikan inovasi-inovasi yang terbaru bagi unit perusahaan.

2. Seluruh bagian komputer sudah terhubung dalam satu jaringan

3. Mengembangkan aplikasi sendiri, hal tersebut menjadi kekuatan bagi Unit PM 10 karena dapat membuat aplikasi sendiri untuk memenuhi kebutuhan unit.

4. Mengembangkan mesin sendiri, hal ini menjadi kekuatan bagi Unit PM 10 karena dapat membuat mesin sendiri untuk mengurangi pengeluaran untuk kebutuhan akan mesin.

5. Memiliki fasilitas TI yang sudah memadai, hal ini menjadi kekuatan bagi Unit PM 10 karena dengan fasilitas TI yang sudah memadai membantu unit dalam menjalankan proses bisnis.

Weakness.

1. Beberapa pola/sistem lama masih dipertahankan, hal ini menjadi kelemahan bagi Unit PM 10 karena dengan pola/sistem yang lama membuat proses kerja menjadi kurang cepat dan tidak mengikuti perkembangan.

2. Karyawan yang kurang paham dalam menggunakan sistem, hal ini menjadi kelemahan bagi Unit PM 10 karena dengan kurangnya pemahaman dalam menggunakan sistem membuat data yang di-inputkan menjadi kurang lengkap sehingga ketika dibutuhkan menjadi kendala.

3. Kurang responsif aplikasi karena data yang banyak tertumpuk, hal ini menjadi kelemahan bagi Unit PM
10 karena dengan banyaknya data yang ada di database membuat sistem lama dalam membaca data, dimana hal tersebut membuat proses pengolahan data unit perusahaan menjadi terhambat.

Opportunity.

1. Memberikan inovasi-inovasi terbaru, hal ini menjadi peluang bagi Unit PM 10 karena dengan inovasiinovasi terbaru yang diberikan dapat membantu unit bersaing dengan perusahaan yang lain.

2. Tersedianya SDM SI/TI, hal ini menjadi peluang bagi Unit PM 10 karena dengan memiliki SDM SI/TI sendiri unti dapat mengambangkan SI/TI sendiri dan mengurangi biaya pembelian atau sewa SI/TI dari pihak ketiga.

3. Menciptakan sebuah teknologi yang baru, hal ini menjadi peluang bagi Unit PM 10 karena dapat memberikan nilai lebih dari perusahaan yang lainnya. Dan dapat maju satu langkah dari perusahaan yang lain.

Threat .

1. Aplikasi crash karena kurang responsif, hal ini menjadi ancaman bagi Unit PM 10 karena aplikasi yang crash dapat menghambat pengolahan aplikasi atau dapat terjadi hilangnya data perusahaan.

2. Kesalahan dalam penggunaan sistem aplikasi, hal ini menjadi ancaman bagi Unit PM 10 karena dengan penggunaan aplikasi yang salah dapat mempengaruhi kualitas data, sehingga ketika diperlukan menjadi kendala ketika data tidak dapat disajikan.

\subsubsection{Analisis PEST}

PEST merupakan sebuah metode untuk mempengaruhi perkembangan bisnis organisasi dalam perusahaan yang dapat dilihat dari sisi politik, ekonomi, 
sosial, serta teknologi untuk mencapai tujuan. Penjelasan PEST Unit PM 10.

1. Politik

Kebijakan pemerintah berupa kebijakan pajak dan bea masuk memberikan pengaruh terhadap nilai jual produk yang nantinya akan berpengaruh terhadap daya saing perusahaan di pasar global.

2. Ekonomi

Dari sisi ekonomi, tingkat inflasi nilai tukar rupiah serta kebijakan pemerintah dibidang ekonomi memberikan pengaruh terhadap nilai jual produk sehingga membuat unit PM 10 harus menjaga keuangan.

3. Sosial

Berdasarkan banyaknya kebutuhan berbagai ragam jenis kertas yang ada di masyarakat, memberikan pengaruh terhadap daya juang dan daya saing perusahaan, selain itu juga mempengaruhi terhadap peningkatan kompetensi dan pencapaian visi misi unit PM 10.

4. Teknologi

Teknologi merupakan salah satu kunci yang ditanamkan dalam unit PM 10, dengan teknologi unit PM 10 mendapatkan kemudahan dalam mencari informasi untuk inovasi-inovasi terbaru bagi unit, kemudahan dalam mencari informasi bagi pelanggan serta kemudahan dalam menjalankan sistem produksi.

\subsection{Analisis Lingkungan Internal dan Eksternal SI/TI}

Teknologi merupakan hal yang sangat penting saat ini dalam membantu perusahaan/organisasi dalam mencapai sebuah keberhasilan. Unit PM 10 PT Pura Barutama merupakan salah satu unit yang sudah mengimplementasikan teknologi dengan sangat baik. Saat ini hampir semua aplikasi dibuat dan dikembangkan sendiri, aplikasi yang digunakan oleh unit PM 10 dalam menunjang proses bisnis antara lain : SIMPRO (aplikasi yang digunakan dalam proses produksi), SIMPG (aplikasi yang digunakan untuk pembelian, gudang sparepart serta bahan baku, PAYROLL (aplikasi yang digunakan untuk penggajian karyawan), SISDM (aplikasi yang digunakan untuk pencatatan data karyawan), PERSONAL INFORMATION (aplikasi yang digunakan untuk pencatatan kunjungan tamu). Serta unit PM 10 juga menggunakan aplikasi pihak ketiga yaitu DESIGNER \& PRINTING LABELING/BARCODE yang digunakan untuk membantu dalam pembuatan label maupun barcode.

Unit PM 10 juga menggunakan database Oracle sebagai media penyimpanan data dari aplikasi yang digunakan, serta jaringan yang digunakan sudah terintegrasi dan terhubung dengan jaringan pusat. Namun berdasarkan hasil pengamatan saat ini yang menjadi kendala pada unit PM 10 yakni data yang terdapat di aplikasi terlalu banyak sehingga membuat kinerja aplikasi dalam membaca data menjadi sangat lambat serta masih terdapat beberapa karyawan yang masih belum memahami dalam mengoperasikan aplikasi. Oleh karena itu dibutuhkan maintenance terhadap data aplikasi yang sudah mulai tidak terpakai dan di backup ke tempat yang lain. Unit PM 10 juga sudah melakukan standardisasi antara lain ISO 9001, ISO 14001, ISO 50001, ISO 45001, HALAL, dan FSC.

\subsection{Portofolio Aplikasi}

Portofolio aplikasi McFarlan Strategic Grid memberikan kemudahan dalam pemetaan strategi SI/TI untuk perusahaan. Pemetaan strategi SI/TI memberikan gambaran aplikasi sistem informasi dalam membantu perusahaan dalam melakukan pengembangan strategi SI/TI yang akan mendatang.

Tabel 2. Portofolio Aplikasi McFarlan Strategic Grid

\begin{tabular}{|l|ll|}
\hline \multicolumn{1}{|c|}{ STRATEGIC } & HIGH POTENTIAL \\
\hline$-\quad$ Aplikasi Business & - & Aplikasi Purchase \\
Intellegence Gudang & & Request \\
Opname & - & SI SDM \\
& - & Sistem Pengelolaan \\
& & Data \\
\hline$-\quad$ Aplikasi Perhitungan & & \\
Harga & & \\
Aplikasi Mobile & \\
Penjualan \& Permintaan & - & Aplikasi $e$-training \\
Aplikasi Mobile Stok & - & Aplikasi Sertifikasi \\
Gudang & & Reminder \\
\hline KEY OPERATIONAL & & SUPPORT \\
\hline
\end{tabular}

Keterangan pada Tabel 2.

1. Strategic merupakan aplikasi yang sangat penting terhadap proses bisnis untuk mempertahankan binis.

2. Key Operational merupakan aplikasi yang saat ini menjadi keberhasilan perusahaan.

3. High Potential merupakan aplikasi yang dapat menjadi potensial untuk mencapai kesuksesan perusahaan.

4. Support merupakan aplikasi yang valuable tapi bukan menjadi hal yang sangat penting.

\subsection{Rencana Implementasi}

Rencana Implementasi SI/TI disesuaikan sesuai dengan portofolio aplikasi yang sudah dipetakan dalam McFarlan Strategic Grid. Pada perencanaan implementasi ini membantu perusahaan dalam mengembangkan sistem informasi dengan menggunakan skala prioritas. Tabel Perencanaan Implementasi. 
Tabel 3. Rencana Implementasi

\begin{tabular}{|l|l|l|l|l|l|}
\hline \multirow{2}{*}{ Rekomendasi } & \multicolumn{5}{|c|}{ Prioritas } \\
\cline { 2 - 6 } & I & II & III & IV & V \\
\hline Aplikasi & & & & & \\
Intellegence & & & & & \\
Gudang Opname & & & & & \\
\hline Aplikasi & & & & & \\
Perhitungan & & & & & \\
Harga & & & & & \\
\hline Aplikasi Mobile & & & & & \\
Penjualan \& & & & & & \\
Permintaan & & & & & \\
\hline Aplikasi Mobile & & & & & \\
Stok Gudang & & & & & \\
\hline Aplikasi & & & & & \\
Purchase & & & & & \\
Request & & & & & \\
\hline SI SDM & & & & & \\
\hline Sistem & & & & \\
Pengelolaan & & & & \\
Data & & & & & \\
\hline Aplikasi $e-$ & & & & \\
training & & & & \\
\hline Aplikasi & & & & \\
Sertifikasi & & & & \\
Reminder & & & & & \\
\hline
\end{tabular}

Keterangan pada Tabel 3.

1. Prioritas pertama adalah Aplikasi Business Intellegence Gudang Opname dan Aplikasi Perhitungan Harga.

2. Prioritas kedua adalah Aplikasi Penjualan \& Permintaan, Aplikasi Mobile Stok Gudang dan Sistem Pengelolaan Data.

3. Prioritas ketiga adalah SI SDM.

4. Prioritas keempat adalah Aplikasi Purchase Request dan Aplikasi Sertifikasi Reminder.

5. Prioritas kelima adalah Aplikasi e-training.

\section{KESIMPULAN}

Berdasarkan hasil analisis dan pembahasan pada penelitian ini dapat disimpulkan bahwa penggunaan SI/TI pada Unit PM10 PT Pura Barutama Kudus masih dijumpai kekurangan dan perlu dikembangkan lagi SI/TI-nya untuk membantu perusahaan menjadi unggul dan memiliki nilai kompetitif. Oleh dari itu, rekomendasi yang diberikan untuk dapat diimplementasikan yaitu: Aplikasi Business Intellegence Gudang Opname, Aplikasi Perhitungan Harga, Aplikasi Mobile Penjualan \& Permintaan, Aplikasi Mobile Stok Gudang, Aplikasi
Purchase Request, SI SDM, Sistem Pengelolaan Data, Aplikasi e-training, Aplikasi Sertifikasi Reminder. Aplikasi yang diusulkan dalam diimplementasikan dalam jangka 5 tahun.

\section{SARAN}

Pada penelitian ini hanya berfokus pada proses bisnis secara keseluruhan, oleh karena itu saran ke depannya yang dapat diberikan untuk penelitian selanjutnya dapat memberikan perencanaan strategis SI/TI yang berfokus pada proses produksi yang lebih mendalam.

\section{DAFTAR PUSTAKA}

Anggraeni, E. Y. 2017. Pengantar Sistem Informasi. Penerbit Andi.

Celta, B. dkk. 2018 Perancangan Strategis PD BKK Susukan Kabupaten Semarang menggunakan Metode Ward and Peppard, Repository UKSW. Universitas Kristen Satya Wacana.

Davis, W. S., \& Yen, D. C. (Eds.). 2019. The information system consultant's handbook: Systems analysis and design. CRC press.

Grant, K., Hackney, R., \& Edgar, D. 2010. Strategic information systems management. Cengage Learning EMEA.

Irwansyah, E., \& Moniaga, J. V. 2014. Pengantar Teknologi Informasi. Deepublish.

Iskandar, T. 2016. Penyusunan Strategi Sistem Informasi/ Teknologi Informasi pada Apotek Cahaya Mitra Menggunakan Metode Ward and Peppard. Universitas Kristen Satya Wacana.

Peppard, J., \& Ward, J. 2016. The strategic management of information systems: Building a digital strategy. John Wiley \& Sons

Rahardja, Y., \& Sitokdana, M. N. N. 2019. Perencanaan Strategis Sistem Informasi Menggunakan Metode Ward And Peppard Pada PT. Serasi Autoraya. Sebatik, 23(1), 185-191.

Setyono, Y. A., Wijaya, A. F, Sitokdana, M. N. N. 2019. Perencanaan Strategis Sistem Informasi Menggunakan Ward and Peppard (Studi kasus: Gereja Kristen Jawa Plengkung). Universitas Kristen Satya Wacana.

Suryana, D. (Ed.). 2012. Mengenal Teknologi: Teknologi Informasi. CreateSpace Independent Publishing Platform. 